\title{
Research on the Influence of Alternating Electromagnetic Field on Conductivity of Hard Water
}

\author{
Yong Han $^{1}$, Xiao Wang $^{2}$ and Shutao Wang ${ }^{1, *}$ \\ ${ }^{1}$ Measurement Technology and Instrumentation Key Laboratory of Hebei Province, School of \\ Electrical Engineering, Yanshan University, 438 Hebei Street, Hai Gang, Qinhuangdao 066004, China \\ ${ }^{2}$ School of Science, Harbin Institute of Technology, 92 West street, Nan Gang, Harbin, 150001, China \\ ${ }^{*}$ E-mail: wangshutao@ysu.edu.cn
}

doi: $10.20964 / 110403123$

Received: 15 January 2016 / Accepted: 22 February 2016 / Published: 1 March 2016

The influence to the conductivity of the hard water caused by alternating electromagnetic field was investigated. Through experimental research it was found that the hydrolysis reaction in the hard aqueous solution was promoted during alternating electromagnetic field treatment. The promoted hydrolysis reaction was considered as the main cause for the change of the conductivity, and further more was considered as the anti-fouling mechanism of alternating electromagnetic field treatment because promoted hydrolysis reaction decreased hard water's $\mathrm{pH}$ value. Through the experiment research the optimized frequency and output power of excitation signal were also investigated to make more promotion to the hydrolysis reaction in solution.

Keywords: Alternating electromagnetic field; Conductivity; Anti-fouling; Calcium carbonate; Hydrolysis reaction

\section{FULL TEXT}

(C) 2016 The Authors. Published by ESG (www.electrochemsci.org). This article is an open access article distributed under the terms and conditions of the Creative Commons Attribution license (http://creativecommons.org/licenses/by/4.0/). 